\title{
Development of Prototype Protection Setup for Standalone Solar Power System
}

\author{
Titu Bhowmick, Dharmasa \\ Department of Electrical and Computer Engineering, Caledonian College of Engineering, AL Hail, Oman
}

Email address:

titu11500@gmail.com (T. Bhowmick),rdharmasa@gmail.com (Dharmasa)

\section{To cite this article:}

Titu Bhowmick, Dharmasa. Development of Prototype Protection Setup for Standalone Solar Power System. American Journal of Electrical Power and Energy Systems. Vol. 4, No. 6, 2015, pp. 100-105. doi: 10.11648/j.epes.20150406.13

\begin{abstract}
This paper presents development of an electrical protection scheme using Arduino microcontroller for a prototype solar power system. First, literature review is carried out on numerical relays for the protection scheme having solar panel output of $12 \mathrm{~V} \mathrm{DC}$, which is then converted into $220 \mathrm{~V}$ AC power output using an inverter. Specifically two types of faults are demonstrated neglecting the fault impedance: (i) Over Current fault; (ii) Differential Overcurrent fault. Subsequently, as per the magnitude of the fault current, an Inverse-Definite Time (IDMT) characteristics are studied to preset the operational features of a relay. Afterwords, the relay signals are programmed using an Arduino Microcontroller. The proposed setup consists of $115 \mathrm{~V} / 15 \mathrm{~V}$ transformer; $50 \mathrm{~W}$ variable rheostat; electro-mechanical relay and low burden electronic current sensors (ACS712) to measure fault current. Then 220V AC auto-transformer is used to tap the voltage to a level of $115 \mathrm{~V}$ as per the opted transformer. The work identifies the difference between the magnitudes of input-output of currents of a transformer and if magnitude is more than the pre-set value in $\mathrm{AC}$ section, finally a tripping signal will operate to disconnect the abnormal part. Further, setting of differential relay is investigated to find the efficient operation of the solar power system. Then validation of prototype model is done by creating an intentional fault using variable rheostat as load. This work investigates efficiently to obtain accurate results on both internal and external faults. In total the proposed scheme consumes less power, which is suitable to develop a prototype protection scheme.
\end{abstract}

Keywords: Arduino, Differential Relay, Overcurrent Relay, Inverter, ACS712 Current Sensor, Rheostat

\section{Introduction}

Present power system is in need of a high level of redundancy and reliable protection devices along with the periodic maintenance to keep the system healthy. For that, the relays must be pre-set to an accurate time of interval operation for the system under faulted condition and also monitor continuously scan to keep the system healthy. As per [1] Microcontroller Based Protection Relays (MBPR) have a real time embedded system and in case of abnormal variation of parameters in the system, then [MBPR] must operate in precise with programmed time-delays In these circumstances, there is need of an efficient protection scheme. Recently as per [2] MBPRs are programmed to monitor the health of DC trip coil circuits. MBPR will also help to validate signal status of inputs and output circuits. Further MBPR can be used to monitor the status of transformer breaker, auxiliaries and ambient environmental conditions using efficient communication links.

\subsection{Problem Definition}

Usually, power failures cause either short or long duration power cut in an electrical power distributed area. Which indicates that fault can be triggered due to numerous causes such as: short circuit; overloading; faults in electric generation, transmission and distribution.

The Quality of Power is an important issue for certain utilities such as: mines; hospitals and telecommunication systems. For these utilities the power outage should be minimized to keep the system in continuous operation. In general, voltage events are classified as: Under voltageslong term variations lasting more than 1 minute and if less than $90 \%$ of nominal voltage; Over voltages:-long term variations lasting more than 1 minute and if greater than $110 \%$ of nominal voltage; sags:- short term variations of duration less than 1 minute and the voltage is between $10 \%$ and $90 \%$ of nominal; Swells:- short term variations of duration less than 1 minute and the voltage is greater than 
$110 \%$ of nominal; Voltage unbalance: voltage on each phase conductor is different. The power interruption is more serious in a "Standalone Prototype Solar Power System". The updated, IEEE guide reported in 2011 presently available [3] - includes significant changes and additions like: Differential Relay - Primary Phase Fault Protection; Distance Relay Backup for System; Generator Zone Phase Faults; for Generators 100 \% Stator Ground Fault Protection and TimeOvercurrent Ground Relay.

\subsection{Types of Power Failures}

To achieve the power quality, it is necessary to understand failure classifications and impact of duration of fault on system:

i. Voltage reduction in the network, it can be visually observed by the dimming of the lights. If this fault persists then it will cause damage to the health of the system and also leads to certain equipment to malfunction, due to rise in current magnitude.

ii. Voltage rise occur mainly due to switching or lightning phenomena in the system. This instantaneous effect results in malfunctioning of the equipment and damage to certain machines.

iii. Blackout is the extreme cause of power failures. It isolates a whole network from electricity for a long duration of time, until the fault is rectified. It is mostly caused due to tripping in the power stations. It is still challenging to solve the issue.

\subsection{Need of Protection Scheme for Power System to Reduce Power Failures}

In a power system, all the equipment should operate efficiently without any interruptions and meeting demand of power. In case of sudden increase in demand the power station would not be able to provide the required power and it could cause overloading. Conventionally, solid state protection relays and fuses are used in numerous places to detect these odd effects and cut off the system to avoid any chance of damage mainly due to over current. The simulation study of injection of renewable energy such as solar power into the power grid is reported [4] considering occurrence of overvoltage in distribution feeder. If large amount of solar power is injected at low power demand, then the role of operation of overcurrent relays becomes more critical due to reverse power operation at $33 \mathrm{kV}$ bus. In case of small-sized power grid bi-directional inverters on AC buses in charging battery banks and adjusting the relay current settings.

In [5] authors are reported simple MPBR approach, which operates as per strict-time based protection deadlines such as i) Overloading of electrical equipment, it is not always necessary to have sudden operation of protective relaying, for such conditions definite real time operations are suitable. ii) In case of long duration short circuit fault to avoid damage of the equipment, sudden removal is necessary.

In recent years good- quality research is reporting, in this topic to improve the reliability of the protection devices. Failures can occur in any part of the system and in any equipment, protection devices are aimed to protect the assets and guarantee continued supply of power, even under sudden inrush of current.

\subsection{Overcurrent Relay}

The most severe type of fault in a system is over load fault; where it can develop heat $\left[\mathrm{I}^{2} \mathrm{Rt}\right]$ in the equipment and then damage the system. In case of Short Circuit, disconnection of the power system for high magnitude over current $\left(\mathrm{I}_{\mathrm{sc}}\right)$ due to improper setting of disconnection time. Hence, there is a greater risk of blackout of electrical power supply area. As per IET regulations, in case of distribution system graded current range selected for the current carrying conductor as per equation (2):

$$
\mathrm{I}_{\mathrm{b}} \leq \mathrm{I}_{\mathrm{n}} \leq \mathrm{I}_{\mathrm{z}} \leq \mathrm{I}_{\mathrm{sc}}
$$

Where,

$$
\begin{aligned}
& \mathrm{I}_{\mathrm{b}}=\text { Design Current } \\
& \mathrm{I}_{\mathrm{n}}=\text { Fuse setting Current [Nominal value] } \\
& \mathrm{I}_{\mathrm{z}}=\text { Perspective current } \\
& \mathrm{I}_{\mathrm{sc}}=\text { Short Circuit current } \\
& \qquad \mathrm{Iz}=\mathrm{I}_{\mathrm{n}} / \mathrm{C}_{\mathrm{a}} \mathrm{C}_{\mathrm{g}} \mathrm{C}_{\mathrm{i}} \mathrm{C}_{\mathrm{h}}
\end{aligned}
$$

Where, $C_{a}, C_{g}, C_{i}, C_{r}$ are the correction factors used to design a current carrying conductor as shown in equation (2).

$\mathrm{C}_{\mathrm{a}}=$ Conductor under ambient temperature

$\mathrm{C}_{\mathrm{g}}=$ Grouping of cables having conductors

$\mathrm{C}_{\mathrm{i}}=$ Thermal insulation of cable covering conductor

$\mathrm{C}_{\mathrm{h}}=$ Presence of Harmonic in the current

The conventional Electro-Mechanical induction overcurrent relays are used as an energizing coil through which the current passes [6]. In such case, a circuit must be completely ON or OFF with minimal on-state voltage drop. In such case an Electro-Mechanical Relay [EMR] is the only choice. EMRs also are best, if heavy surge currents or intermittent voltages are anticipated from the load side. In normal conditions, the current is not sufficient to produce magnetic field to move the disc. In abnormal conditions when the current is very high, the coil produces large magnetic fields that move the disc and trigger the tripping of the breaker. The work considers solid -state relays (SSR)s relays as electronic devices. Usually, an SSR's input consists of an Opto-isolator, while its output is a Triac, SCR, or FET. One negative aspect of an SSR is that semiconductors are never completely on or off. In the on-state, substantial resistance is present, which can lead to significant heat generation when current is flowing. So SSRs must be placed on heat sinks, often several times the relay's weight. SSR sensitive to ambient heat and must be de-rated if used in hot environments country like Oman in the Gulf region.

Improved and advanced versions of the overcurrent relay is embedded in the digital relays, which determine in precision the abnormality of the system conditions.

Overcurrent protection motor [7] protection setup is as shown in Fig. 1 for three phase network. In this arrangement, an instrument transformer is used such as current transformer 
(CTs), which take the current reading and sends analog values to the controller/processor in voltage from. First, controller converts the digital and then compares them to a preset value. The preset value is the current ratings of the system during normal condition.

In case of abnormal conditions the current reading will exceed the preset value and then the controller will send the tripping signal. Inverse Definite Minimum Time (IDMT) over current protection is used as the relay settings. This has an advantage of dealing with the severity of the fault current. If the fault current is high, the controller will send the tripping signal fast otherwise after a time delay. The time delay is set using standard equation (1):

$$
t=T M S \times\left\{\left[\frac{k}{\left(\frac{I}{I s}\right)^{a}-1}\right]+c\right\}
$$

Where,

$\mathrm{t}=$ operating time; $\quad \mathrm{I}=$ energizing current;

$\mathrm{I}_{\mathrm{s}}=$ overcurrent setting; TMS $=$ Time Multiplier Setting.

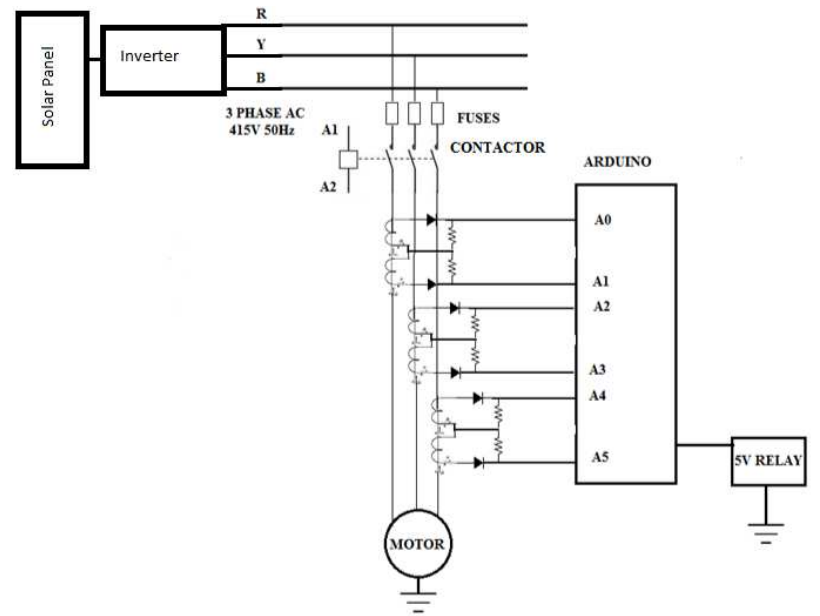

Fig. 1. Overcurrent motor protections circuit.

\subsection{Differential Relay}

This relay is basically unit-type or for a specific equipment protection. It functions to detect any internal faults in its zone of protection. It takes the current readings and checks the differential in the current entering and leaving as per simple KCL technique. Current Differential relays are basically applied to transformer giving rating upto 5 MVA and above (on transformers which are critical to operate) Transformers have Buchholz relay installed in them that monitors the internal health of the transformer using the insulating oil, but it cannot detect any inter turn-fault occurred to the transformer. For that differential relay is used, these relays detect any difference in the transformer accurately and quickly.

For current differential relay, current transformers are used to read the current values on the primary and the secondary side. The readings are sent to the controller, where they are compared and any abnormal condition is detected if the compared value is different from the preset value.

\section{Proposed Methodology}

Fig. 2 shows that there are two solid-state current sensors i.e. one at the primary side and other at the secondary side of the transformer. The transformer gets $115 \mathrm{~V}$ as primary voltage from the supply, through a contactor. For this supply, current sensors give the analog current reading to the analog inputs of the Arduino A1 and A2. The current sensors take $5 \mathrm{~V}$ power supply from the Arduino.

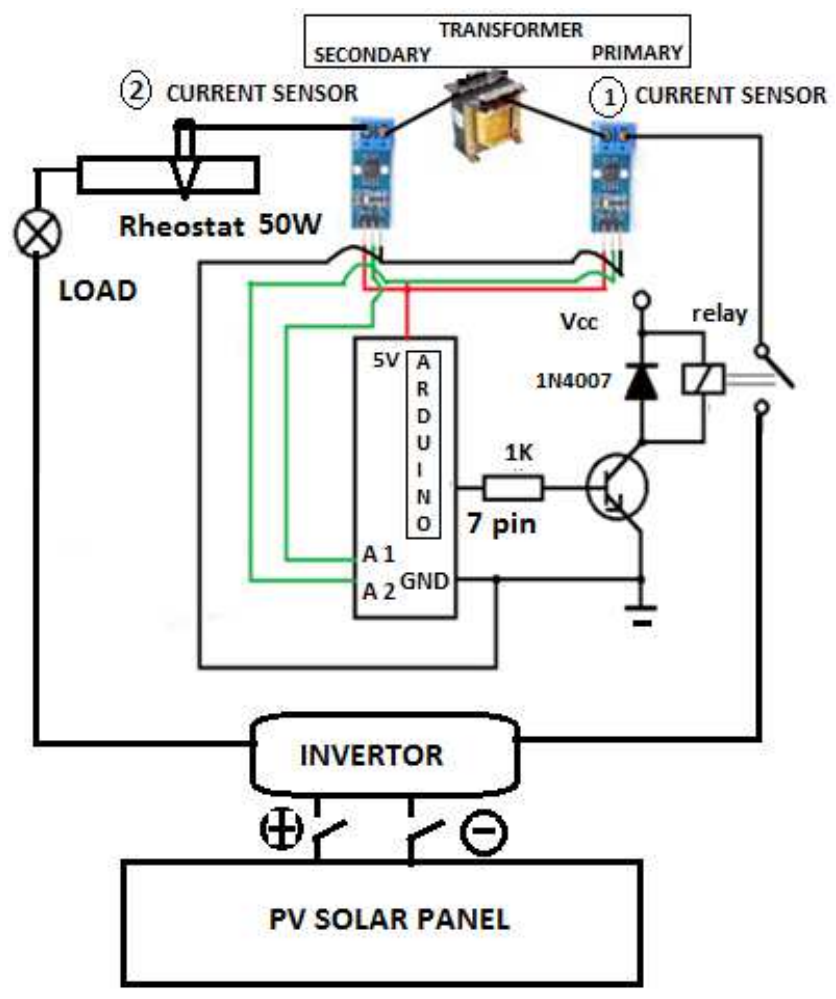

Fig. 2. Proposed protection setup.

Arduino can only handle voltage (between $0 \mathrm{~V}$ and $5 \mathrm{~V}$ ), so it is necessary to convert this current into an acceptable voltage range. As per [8] a burden is added in resistor circuit as shown in Fig. 3(b) for Fig. 3(a) model (YHDC SCT-013-000) CT.

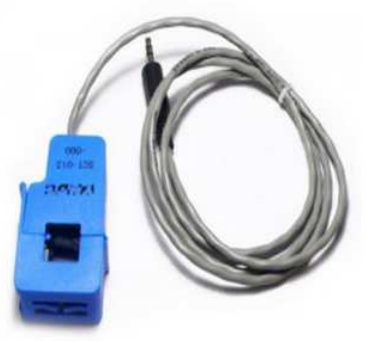

(a)

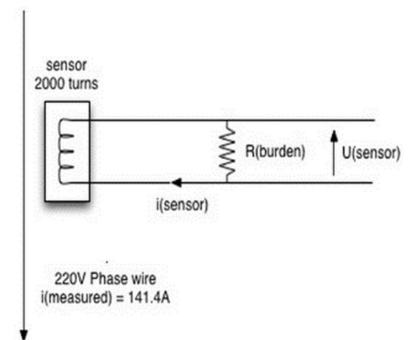

(b)
Fig. 3 (a, b). AC current sensor with I to V circuit.

From Fig 3(b), it can be expressed clearly that the current is alternative around 0 and $5 \mathrm{~V}$ to maximize measurement resolution and the max voltage at burden resistance is $2.5 \mathrm{~V}$. The better Burden resistor value opted using $\mathrm{R}$ (burden) = $\mathrm{U}($ sensor $) / \mathrm{I}($ sensor $)=2.5 \mathrm{~V} / 0.0707 \mathrm{~A}=35.4 \Omega$. The 
maximum phase error of 4 degree for $18 \Omega$ burden is insignificant (representing a power factor error of less than 0.0025 at unity power factor), but the error of nearly 10 degree with a $120 \Omega$ burden could be troublesome with low current loads having a poor power factor where this input is most likely to be used and such type sensor are used for only AC current measurement. The opted sensor of [9] has applied current flowing through the copper path and it generates a magnetic field based on Hall IC converts into proportional voltage and it also be used for Output voltage proportional to AC or DC currents.

Fig 4 shows the secondary side of the transformer is operating at $15 \mathrm{~V}$ (load). A rheostat and light bulb act as load, which indicates the flow of current. The primary side ACS712 current sensor as [10] is found more suitable for the over current protection of the transformer and the secondary side current sensor is used for the differential current value to indicate any internal faults in the transformer. In case of abnormal conditions the Arduino gives a tripping signal to the relay through pin 7 , and the relay is connected with the contactor, which disconnects the circuit from the supply.

The sensors were tested to find out the accuracy based on the output of the device has a positive slope [>VI OUT(Q)] when an increasing current flows through the primary copper conduction path (from pins 1 and 2, to pins 3 and 4), which is the path used for current sampling. The internal resistance of this conductive path is 1.2 milliohm, which is typical to provide low power loss.

The reading of the sensor is tabulated in Table 1 and the order variable reading are obtained using rheostat.

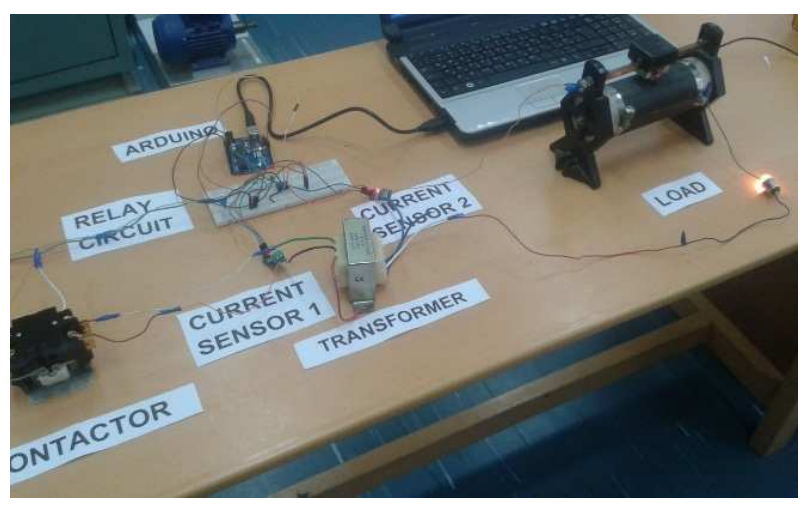

Fig. 4. System under operation status.

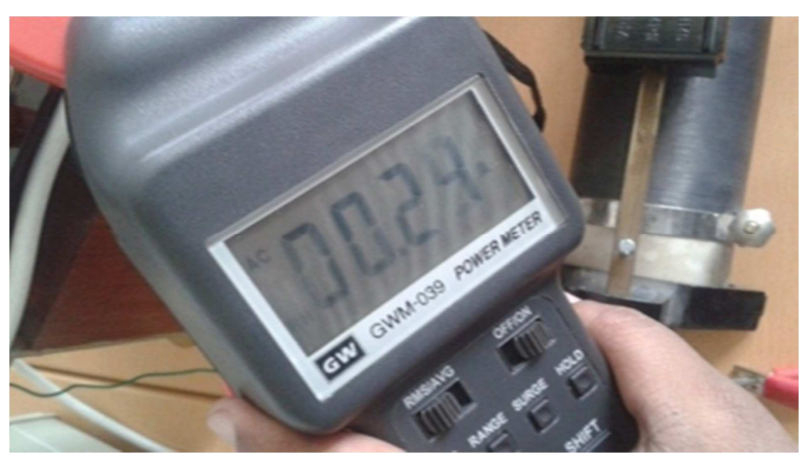

Fig. 5. Current reading using a clamp meter.
The sensors take the current reading and it is displayed on a screen connected with the Arduino shown in Fig.4 The sensors were used and the accuracy was tested for providing power supply through USB and found that $0.005 \mathrm{~A}$ is tolerant. The set values were accurately read from the load current and computed as shown in Fig. 5.

Table 1. Current sensor measurements.

\begin{tabular}{ll}
\hline Sl. No. & Current (A) \\
\hline 1 & 0.27 \\
2 & 0.26 \\
3 & 0.26 \\
4 & 0.26 \\
5 & 0.25 \\
6 & 0.25 \\
7 & 0.25 \\
8 & 0.25 \\
9 & 0.25 \\
10 & 0.25 \\
\hline
\end{tabular}

\section{Results and Discussions}

The load is varied using variable rheostat having small $50 \mathrm{~W}$ capacity to reduce high current in the primary side. The readings taken by the sensors and then send to the Arduino. Usually, a relay will act in an inverse time overcurrent relay mode. The Arduino compares the value with the Pre-set value, if the fault magnitude (over-load) more than pre-set value, then Arduino sends the trip signal after a time delay.

If the fault magnitude is suddenly rises to a higher (short circuit) value than the pre-set value, the Arduino sends an instant trip signal. If the sensor read more than set value of current, then sensor sends the data to the Arduino which compares the value with a preset value and finally protection setup operate after a time delay.

The prototype of transformer is used in the circuit having nearly a current of $1 \mathrm{~A}$, for that a preset value is $0.7 \mathrm{~A}$ and this set value is sufficient to operate the Arduino. The load was varied to reach this point and when a value sensed is above 0.7A, The Arduino sends the tripping signal to the relay and shows that there is an external fault in the system which caused the tripping. The results for external faults are as tabulated in Table 2 .

Table 2. Indicating External Fault.

\begin{tabular}{lllll}
\hline $\begin{array}{l}\text { SI } \\
\text { No. }\end{array}$ & $\begin{array}{l}\text { Primary } \\
\text { current (A) }\end{array}$ & $\begin{array}{l}\text { Secondary } \\
\text { current (A) }\end{array}$ & $\begin{array}{l}\text { Current } \\
\text { ratio }\end{array}$ & Fault \\
\hline 1 & 0.68 & 0.71 & 0.95 & No Fault \\
2 & 0.67 & 0.70 & 0.96 & No fault \\
3 & 0.67 & 0.67 & 1.00 & No Fault \\
4 & 0.72 & 0.71 & 1.02 & Fault Indicated \\
\hline
\end{tabular}

For the operation of differential relay the transformer internal faults are created and the preset value of the difference in the primary and secondary current was set low. Setting leads to send the trip signal in case of any internal faults. 
Table 3. Indicating internal fault.

\begin{tabular}{lllll}
\hline $\begin{array}{l}\text { Sl. } \\
\text { No. }\end{array}$ & $\begin{array}{l}\text { Primary } \\
\text { current (A) }\end{array}$ & $\begin{array}{l}\text { Secondary } \\
\text { current (A) }\end{array}$ & $\begin{array}{l}\text { Current } \\
\text { ratio }\end{array}$ & Fault \\
\hline 1 & 0.66 & 0.70 & 0.94 & No Fault \\
2 & 0.66 & 0.70 & 0.94 & No fault \\
3 & 0.66 & 0.68 & 0.97 & No Fault \\
4 & 0.67 & 0.65 & 1.02 & No Fault \\
5 & 0.65 & 0.73 & 0.89 & Fault Indicated \\
\hline
\end{tabular}

This differential relay finds any possibility of internal faults and later. Differential relay acts as a protection for the transformer from being exposed to current, high temperature and pressure in case of any internal faults, which would further lead to flashover of the transformer. The relay trips the system in the rise in differential current value above the preset value. The preset value was set at 0.9A.Excavation of any change in the difference in current caused by internal faults of the transformer as shown in the Table 3 drafted from result seen on laptop display, which indicate an internal fault. For that type of fault, the currents characteristics of transformer need to be further inspected.

The system setup and the relay are tested in the real time. The result indicates that the relay works as IDMT relay and trips the circuit in case of any abnormal conditions for the overcurrent preset value at $0.7 \mathrm{~A}$. The set value is detected and the relay opened the circuit using the contactor. The tabulated fourth reading of Table 2 indicates unacceptable current value, i.e. abnormal current value, which sensed by the relay and disconnects the circuit with help of Arduino. The fifth reading of the Table 2 result shows abnormal condition as an External Fault.

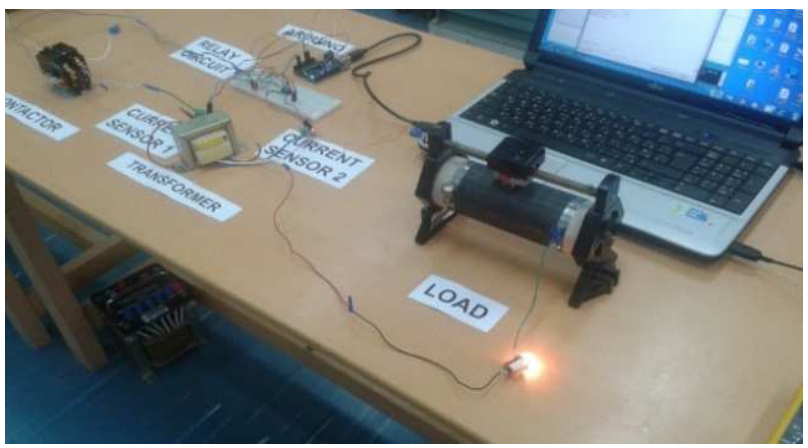

Fig. 6. Circuit under normal working conditions

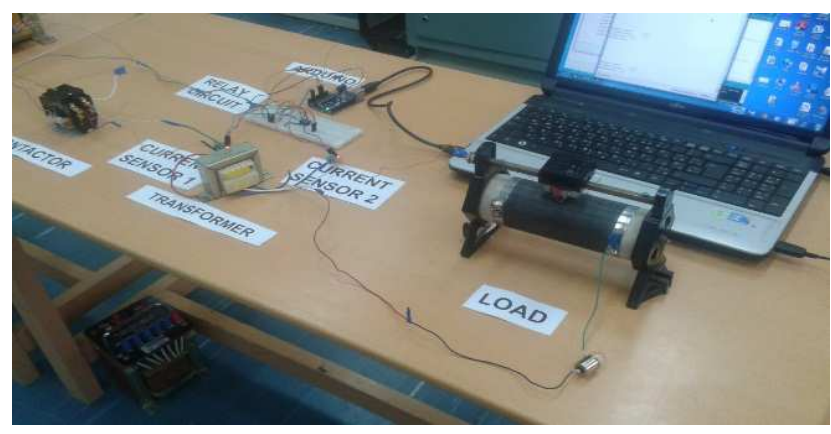

Fig. 7. Circuit under abnormal conditions.

Furthermore the connection diagrams for normal conditions and abnormal conditions are presented in Fig 6 and 7 respectively. If there is a change in the load, higher current is drawn from the supply and then sensors read the current value and send the input to the Arduino in the form of voltage signal. This signal is converted into digital form of current value, which is computed by the microcontroller. If the value is higher than the pre-set value the Arduino sends the tripping signal to the relay. In the proposed work, the delay time of $500 \mathrm{~ms}$ was given for current value operated in between $0.7 \mathrm{~A}$ to $0.75 \mathrm{~A}$ and otherwise a direct tripping was done for short circuit value.

Considerations for Using High-Impedance or LowImpedance microprocessor Relays for Bus Differential Protection the transformer can be seen in [10]. There is a wide variety of technologies that are used in today's smart meters for sensing the current submitted [11] delivers the strengths and weaknesses of the most popular sensing technologies. In this case an independent comparison between high and low-impedance bus differential relays is discussed by the authors. Also authors' opinions regarding the superiority of one type of relay over the other for specific considerations discussed in detail [12] for different sensors.

\section{Conclusion}

The proposed overcurrent and transformer differential protection schemes are tested by creating fault using variable resistance. It is found that, numerical or program based relays have better accuracy and less response time, while clearing the faults and also protection parameters can be varied accordingly. In the proposed Arduino the IDMT can be modified or changed using simple programming technique. The actual set values and operational program can be easily viewed in the computer screen or any other preferred monitor. In the developed system, Hall Effect based ACS712 current sensors, and Arduino does not consume much power, while in operation. This is one of the major advantages of the model developed. The Arduino based program relay set-up has more accurate and flexible in fault detection and clearing, when compared to static as well as electromagnetic relays.

\section{References}

[1] Aaditya G. V., Reddy M. S., Rao K. V, Ashish P. C, "project report" Electrical and Electronics Engineering, Gokaraju Rangaraju Institute of Engineering \& Technology, Bachupally, Hyderabad, 2010.

[2] Nollette S., 2014, Microprocessor-based relays offer extra value, Control Engineering [Online]: Available from: http://www.controleng.com/single-article/microprocessorbased-relays-offer-extra-

value/911ed9a6dde5fa4528a3c087a9ab4c3f.html.

[3] Special report on IEEE Power System Relaying Committee, 2011, 57th IEEE Pulp and Paper Industry Conference. [Online]https://www.eiseverywhere.com/file_uploads/ae8b33 3bd131b9146e01907d95ec0fcb_Synchronous_Generator_Prot ection_PPT.pdf. 
[4] Ouahdi Dris Farag. M, Elmareimi Rekina Fouad, "Transformer Differential Protection Scheme With Internal Faults Detection Algorithm Using Second Harmonics Restrain and Fifth Harmonics Blocking Logic, 5th International Conf. On Electrical änd Electronics Engg., 5-9 December 2007, Bursa, Turkey.

[5] Nader Barsoum, Chai Zen Lee, "Simulation of Power Flow and Protection of a Limited Bus Grid System with Injected Solar Power", Energy and Power Engineering, 2013, 5, 59-69.

[6] Kumar V. L and Garividi S. T. I. C, Microprocessor Relay for protection of Electrical System, Ubiquity, 7(20), 2006, p. 15-23.

[7] Thomas R. M "Electromechanical Relays Versus Solid-State: Each Has Its Place", Sep 2002, [Online] Available from: www.electronicdesign.com/components.

[8] Sairam A., Sandeep P, Vilas B, Manideep K, Kumar V. R, "Project Repot" in Electrical and Electronics Engineering, Gokaraju Rangaraju Institute of Engineering and Technology, Bachupally, Hyderabad, 2014.
[9] Vincent Demay, Current monitoring with non-invasive sensor and arduino, [Online]: Available fom: http://www.homautomation.org/2013/09/17/currentmonitoring-with-non-invasive-sensor-and-arduino.

[10] Fully Integrated, Hall Effect-Based Linear Current Sensor IC with $2.1 \mathrm{kVRMS}$ Isolation and a Low-Resistance Current conductor [Online]: Available form: https://maxwell.ict.griffith.edu.au/sok/ees/resources/Current.pdf.

[11] Ken Behrendt, David Costello, Stanley E. Zocholl Considerations for Using High-Impedance or Low-Impedance Relays for Bus Differential Protection 49th Annual Industrial \& Commercial Power Systems Technical IEEE Conference, Stone Mountain, Georgia, April 30-May 3, 2013.

[12] Glenn Roemer, FAE, Pulse Engineering Current Sensors in Power Metering Applications, page-1-4 Available form: http://www.pulseelectronics.com/docs/white_paper.pdf. 